\title{
OTRO DISCURSO HISTÓRICO: LA NOVELA
}

\author{
JOSÉ M. ${ }^{a}$ BERNARDO PANIAGUA \\ Catedratico de Lengua y Literatura de I. B.
}

«El discurso histórico no sigue a lo real, sólo significa sin dejar de repetir: «ha ocurrido». Esa aseveración nunca puede dejar de ser otra cosa que el reverso significado de toda la narración históricam. (Roland Barthes) (1)

Reivindicar para la novela, discurso narrativo, la calificación de discurso histórico, lectura de la realidad con coordenadas historiográficas puede ser una osadía, en ningún caso una estultez, porque es un producto histórico, contextualizado socioculturalmente. Es una lectura de la realidad modelizada de forma especifica, por lo que constituye también un testimonio básico para la investigación histórica y, sobre todo, la novela contemporánea, constituye una explícita alternativa: discurso histórico débil frente a discurso histórico fuerte (historia científica).

Aclarar esta postura exige una triple operación: acercamiento al discurso narrativo e histórico como artefactos lingüísticos, narrativos e historizados o productos culturales; aproximación a los mismos, buscando una interrelación y mejor delimitación; confrontación de los supuestos teóricos provenientes de las operaciones anteriores con la producción de historiadores y novelistas contemporáneos.

\section{EL DISCURSO NARRATIVO}

Entendido el armazón narrativo como el invento del autor-novelista a través de un narrador que, responsable (indiciado en la afición) directo, construye el entramado necesario para relatar, contar una historia de forma dinámica por medio de unos personajes (actantes) que realizan una serie de acciones dentro de un espacio y de un tiempo con la finalidad de transmitir a los 
lectores la visión que dicho autor posee de una realidad (referente) bajo el pretexto, con el modelo, de la ficción.

Es, pues, la narración, el discurso narrativo (la trama, el relato) un producto del autor narrador y a él corresponde crear una lógica narrativa, una ordenación de acciones, un tratamiento del tiempo y del espacio. Constituye, en resumen, un producto mental, conceptualización o ideologización, de un autor que, valiéndose del narrador, manipula arbitrariamente (2), aunque haya de respetar la lógica especifica de ese discurso: la verosimilitud, lógica inherente al discurso imaginario y exigida por la forma de narrar, de contar la historia, puesto que este discurso no está determinado directamente por la dinámica o lógica causal de los hechos, de la realidad, sino por las convenciones discursivas que, al menos en su apariencia -estructura superficialson lingüísticas o narrativas, no históricas ni reales o experienciales (objetivas).

Hablar de normas lingüísticas en el discurso narrativo nos lleva a las consideraciones que en torno al texto ha realizado la llamada Lingüística Textual (3), una teorización surgida desde presupuestos propiamente lingüisticos, filosóficos, comunicacionales y semióticos. Teorización que, partiendo de un supuesto básico: el texto como unidad comunicativa fundamental, ha constituido un completo corpus y un modelo de explicación lingüística coherente $y$ tértil.

Una delimitación del propio término, de carácter más bien descriptivo, puede valernos para acortar el ámbito de nuestro acercamiento al texto con el fin de localizar el discurso narrativo en su dimensión textual correcta. Delimitación que Bernárdez elabora tras el análisis de las definiciones de autores diferentes, con planteamientos lingüísticos diversos, en estos términos: «Texto es la unidad lingüística comunicativa fundamental, producto de la actividad verbal humana, que posee siempre carácter social; está caracterizado por su cierre semántico y comunicativo, así como por su coherencia profunda y superficial, debida a la intención (comunicativa) del hablante de crear un texto íntegro, y a su estructuración mediante dos conjuntos de reglas: las propias del nivel textual y las del sistema de lengua" (4).

Evidencia esta definición básicamente la existencia de unos sujetos interlocutores, corresponsables de la eficacia en la producción textual, creación y recreación (producción de sentido) del mismo (5), la coherencia-cohesión (6) de su estructura y delimitación situacional a través de los elementos pragmáticos (7). Datos que pueden, para nuestro objetivo, leerse de este modo: un emisor transmite una visión de la realidad (establece una hipótesis de lectura) a un receptor, interno o externo; un autor pretende elaborar la lectura de una 
realidad y la presenta, como mensaje, para un lector ideal (8) y para cualquier otro posible lector capacitado de realizar una correcta decodificación, la producción de sentido a través del texto como pretexto (9) y para cumplir dicho objetivo necesita una competencia textual.

Dicha coherencia-cohesión ha de ser establecida a través de recursos fómicos, morfosintácticos y semánticos; así como, y sobre todo, pragmático, pues al decir de $\mathrm{C}$. Segre «más bien, se deben buscar en la situación pragmática todas las condiciones de coherencia de un discurso. Estas condiciones se realizarán explícitamente, bien en la formación de cada una de las frases, o bien, y sobre todo, en su encadenamiento (de aquí la importancia de las frases iniciales, o en los textos escritos, de los títulos): se puede decir que la sintaxis es capaz de introyectar, gramaticalizándola, gran parte de la pragmática» (10).

Los tipos de coherencia han sido descritos de formas diferentes por los autores. Lozano (11) habla de cohesión superficial, coherencia global, coherencia pragmática y coherencia interna o isotopía.

El discurso narrativo, por constituir un tipo de texto, aunque especial, ha de cumplir todos los requisitos de su producción, y en esto coincide, se relaciona, con cualquier otro texto: científico, diálogo, publicidad. No obstante, dicho texto posee los ingredientes suficientes que lo diferencian y delimitan respecto a cualquier otro, sea a partir de la coherencia pragmática como determinante (12) o, de forma más genérica, porque «el discurso literario es un acto lingüístico muy particular, sin una finalidad comunicativa inmediata (de hecho continúa siendo válido incluso para lectores alejados en el tiempo y en el espacio)... El mensaje literario comunica, en algunos casos puede renovar la visión del mundo, y siempre la profundiza. Su apariencia no finalista $y$, viceversa, la importancia de sus efectos, dependen de su muy particular modalidad de comunicación: el emisor (el escritor) desarrolla su obra sólo hasta que completa el mensaje; el receptor (lector) parte del mensaje para interpretarlo, sin preguntar al emisor...»(13).

En resumen, el texto narrativo, una modalidad del literario, constituye un modelo de tratamiento de la realidad diferente de cualquier otro texto, al menos en su estructura superficial ( $y$, por supuesto, tómese como se tome, la estructura profunda) aparece ante el lector como una construcción original: la trama, el relato, reflejan una coherencia-cohesión específica, una ordenación particular de los elementos. No podemos, ni sería demasiado útil ahora, repasar el proceso de configuración (definición y delimitación estructural) seguido por la narración, desde Platón a la moderna narratología, pero sí nece- 
sitamos, a fin de subrayar la especifidad de este tipo de discurso, trazar las líneas básicas que los formalistas, retóricos, estilistas o semióticos han resaltado para caracterizar este discurso, manifestación del significante que construye el artefacto narrativo (14).

Estos teóricos del discurso narrativo (15) inciden fundamentalmente en la consideración de este discurso como la configuración, estructuración coherente, de una ficción con la intencionalidad concreta de ofrecer la visión, el punto de vista, la focalización de una realidad (16) acorde con los supuestos ideológicos del narrador, del novelista. Esta configuración exige un supuesto básico, la verosimilitud, es decir: la construcción coherente, interrelación verosímil de los elementos que forman parte de dicho discurso. En principio, el referente, la realidad circundante y determinante, leída desde el bagaje cultural e ideológico del autor. Desde ahí, con la intención de emitir un mensaje (visión dialéctica, descriptiva o lúdica de esa realidad) se inicia todo el proceso creador, productor del texto narrativo, basado en una competencia semiótica, textual —dominio de los rasgos de coherencia-.

Dicho proceso o dinámica de la producción incluye la invención de un proyecto que pretende dinamizar esa visión de la realidad a través de un entramado accional en torno al cual giran los demás elementos, puesto que las acciones suponen actantes e implican un espacio donde situarse y un tiempo en el que transcurren. La ordenación lineal de dichas acciones constituiría la historia; la ordenación arbitraria, transgresora, constituiria la trama, el relato (17). Todo esto, desde la visión del narrador; el lector, en cambio, es quien desde su competencia lectora, productora de sentido (18) establece la organización del significante que se le presenta, descubriendo una morfosintaxis o fragmentación del texto; una semántica o tratamiento de la realidad y una pragmática o relación narrador-lector a través del lenguaje (19).

Insistimos, para finalizar este apartado, en la exigencia de resaltar la función determinante del narrador en la estructura del invento narrativo que se presenta ante el lector como texto. Es él, y no el autor, quien aparece como índice lingüístico, significante (voz verbal, modo, personaje o acotación) a partir del cual deducimos el tipo de visión que se nos intenta ofrecer (20), el punto de vista o la focalización: visión omnisciente, por encima de la narración; visión por debajo de la narración o visión a la misma altura que la narración.

Estas acotaciones han de entenderse como claves para comprender la hipótesis que pretendemos poner en evidencia, ya que si repasamos la historia de la narrativa observaremos cómo en función de las culturas, de las ideologias dominantes, predomina un tipo de acercamiento a la realidad narrada. 
Al fin y al cabo, un alejarniento de la realidad — la omnisciencia - no es más que el afán de crear el engaño, la ficción de la objetividad, base de la racionalidad y, en muchos casos, del dogmatismo; una difuminación de la voz del narrador, por el contrario, en el entramado de la propia narración es el cambio un intento de evidenciar el acercamiento débil y antidogmático a dicha realidad.

El narrador impone, en nombre del autor, su perspectiva de lectura configurando los personajes, las acciones, el espacio y el tiempo, instrumentos de esa visión desde fuera o del acercamiento a su misma altura. La coherencia del texto narrativo, por tanto, proviene de la correcta trabazón, de la lógica interna del propio relato, que llamaremos verosimilitud o apariencia de verdad, puesto que la fidelidad no ha de referirse a la realidad misma, que se considera radicalmente manipulable al ser básicamente el lenguaje, sino con las reglas lingüístico narrativas del relato.

Lo dicho hasta ahora en torno al discurso narrativo podría inducirnos, por su carácter sistemático y abstracto, al error de considerar la producción literaria y sus protagonistas como entes marginados de la realidad sociocultural en la que funcionan, como individualidades creadoras o intérpretes al margen de cualquier determinación, dentro de la idílica libertad del espíritu (21). Por el contrario, y tal como resalta N. Pizarro, creemos imprescindible hablar de la profunda historización del texto y de cada uno de los elementos que en él intervienen: autor, narrador, personajes, lenguaje, lector. Puesto que el lenguaje y los modelos narrativos, la tematización, tópicos sin duda, no son más que imposiciones del paradigma ideológico, de las matrices o ideologuemas de la culura como producción.

Esta dimensión histórica del texto narrativo, del texto en general, ha sido estudiada desde supuestos distintos, e incluso se ha llegado a dudar de la necesidad de la misma en base al afán excesivo de modelización como manifestación suprema de la sistematización, sobre todo desde el formalismo y estructuralismo, tendencias interesantes para el análisis, pero fragmentadoras por cuanto significan una aproximación descontextualizadora al texto, cuando en realidad «el hecho de hablar significa, como subraya N. Pizarro, más que el significado de los enunciados: significa la realización social reproducida por ellos» (22).

La historización del texto tiene una doble exigencia: la localización de los interlocutores del mismo y la contextualización del producto. Al menos así lo deducimos de este texto de C. Segre: «Al insertar el texto en un acto de comunicación, se evidencian automáticamente sus lazos de unión con la cultu- 
ra y se reivindica una perspectiva histórica. De hecho, el emisor extrae los códigos de que dispone para interpretar el texto. Detrás de la interpretación, existen grandes problemas originados por el encuentro entre dos culturas, y la posibilidad que uns cultura tiene de comprender ( $y$ asimilar) otra precedente. Los sistemas de significación están isntituidos dentro de una cultura y forman parte integrante de ella. Los procesos históricos, como señala Uspenski, son procesos comunicativos; coinciden con las respuestas del destinatario social a las nuevas informaciones ofrecidas por la cultura» (23).

Afirmación que se explicita más en este otro texto del mismo autor: «El ciclo análisis-sintesis-análisis-síntesis represneta en su simplicidad las fases principales de la vida comunicativa del texto. El emisor lleva a cabo un análisis de la realidad experimentada por él (y que comprende todos los elementos de continuidad histórica); lo sintetiza en el texto, recurriendo a los códigos de época de que dispone; el receptor analiza el texto, recurriendo a los mismos códigos de época, y lleva a cabo una síntesis interpretativa.

La historia parece, por tanto, revelarse bajo dos aspectos principales: como contenido histórico y como historicidad de los códigos. En un análisis más atento los dos aspectos resultan más homogéneos, dado que en el texto no importa tanto el dato o la evocación histórica como el "universo imaginario", por decirlo con Goldman, es decir, una historicidad interiorizada y estructurada como sistema. Este "universo imaginario" tiene estatuto de modelo y cosntituye un esquema para el funcionamiento de los códigos» (24).

Con estas afirmaciones estamos insistiendo en algo que las sistematizaciones, básicamente estructuralistas, han pretendido olvidar (25): el sujeto, emisor o receptor, como sujetos reales pertenecientes a una determinada sociedad, formación social y por lo mismo imposibles de ser comprendidos como indivíduos aislados, puesto que pertenecen, y por lo mismo reproducen los intereses de clase que determina cualquier actuación, incluida la producción ideológica y cultural, entiéndase ésta en los términos que se entienda. «El grado de competencia semiótica - subraya N. Pizarro- de los individuos sociales, las variaciones de esta competencia, serían analizadas en función de la pertenencia de los individuos a una clases social determinada, en consecuencia, la noción de clase podría estar relacionada a su vez con el concepto de competencia semiótica y el grado de competencia semiótica de una clase (su capacidad de producir productos significantes) podría estar relacionada de forma más o menos directa con la cantidad de materias primas disponibles...» (26). 


\section{EL DISCURSO HISTÓRICO}

Roland Barthes (27) ha realizado un interesante trabajo en torno al discurso histórico, analizándolo desde la perspectiva semiológica, superando los análisis meramente historiográficos, contenidísticos, al proyectar un modelo de análisis más completo y sistemático que introduce al texto histórico en el amplio ámbito de la teoría de la comunicación, donde deberán tenerse en cuenta todos los elementos que componen el proceso comunicativo.

Digamos, para empezar nuestro análisis del discurso histórico, con el propio Barthes que «A partir del momento en que interviene el lenguaje, el hecho sólo puede ser definido en forma tautológica: lo anotado proviene de lo notable, pero lo notable es - desde Herodoto, en quien la palabra ha perdido ya su aceptación mítica sólo aquello es digno de recordar, es decir, digno de ser anotado. Se llega así a esa paradoja que regula toda la pertenencia del discurso histórico (con relación a otros tipos de discurso): el hecho nunca tiene sino una exigencia lingüística (como término de un discurso) y sin embargo todo ocurre como si esa existencia fuera sólo la 'copia' pura y simple de otra existencia situada en un campo estra-estructural, lo 'real'. Ese discurso es sin duda el único en que el referente es considerado exterior al discurso; sin embargo, nunca es posible encontrarlo fuera del discurso" (28).

Estas primeras acotaciones pueden deducirse de la afirmación introductoria de Barthes presenta en el trabajo ya citado, cuando dice «Esta lingüística (la del discurso) segunda debe investigar los universales del discurso (si existen), bajo la forma de unidades y de reglas generales y, al mismo tiempo, decidir, evidentemente, si el análisis estructural permite mantener la tipología tradicional de los discursos y si es legítimo contraponer aún el discurso poético al discurso novelesco, la ficción al relato. Precisamente sobre este último punto quisiéramos hacer algunas reflexiones: la narración de los hechos pasados, sometida por lo general en nuestra cultura, a partir de los griegos, a la sanción de la ciencia histórica, colocada bajo la imperiosa garantía de lo 'real', justificada por principios de exposición 'racional', ¿difiere realmente por algún rasgo especifico, por una indudable pertinencia, de la narración imaginaria tal como se la encuentra en la epopeya, la novela o el drama?. Y si ese riesgo -o esa pertinencia- existe, ¿en qué lugar del sistema discursivo, en qué nivel de la enunciación hay que situarla?..." (29).

De la respuesta a dicha interrogación, y centrando su atención en el análisis del discurso histórico que ahora nos preocupa. Como enunciación, dicho discurso histórico implica fijarse en el «shifter» de escucha, categoría «identificada, al nivel de la lengua, con el nombre de testimonial por Jakobson y se- 
gún la fórmula $\mathrm{C}^{\mathrm{e}} \mathrm{C}^{\mathrm{a}} / \mathrm{C}^{\mathrm{a} 2}$ : además del hecho $\left(\mathrm{C}^{\mathrm{e}}\right)$, el discurso menciona a la vez el acto del informante $\left(C^{a}\right)$ y la parlabra del enunciante $\left(C^{a 2}\right)$ que se refiere a ese acto. Ese shifter designa, pues, toda mención de fuentes y testimonios, toda referencia a una 'forma de escuchar' del historiador que recoge una 'aufera' de su discurso y lo dice» (30); shifter, por lo demás, que «no es pertinente al discurso histórico; se lo encuentra con frecuencia en la conversación y en ciertos artificios de exposición de la novela (anécdotas contadas según ciertos informantes ficticios de los que se hace mención)» (31).

Por otra parte, los que podríamos denominar shifters de organización: «todos los signos declarados por medio de los cuales el enunciante, en este caso el historiador, organiza su propio discurso, lo retoma, lo modifica a lo largo de su camino, en una palabra, le asigna referencias explícitas» (32). La problemática que conllevan estos shifters de organización «nace de la coexistenciao mejor dicho, del roce de dos tiempos: el tiempo de la enunciación y el tiempo de la materia enunciada" (33). Coexistencia que dará lugar a hechos del discurso imprtantes, referidos al proceso mismo de la enunciación:

-Aceleración de la historia.

-Profundización del tiempo histórico en torno a determinados personajes.

-Destrucción del espacio crónico de la historia.

Conjunto de fenómenos discursivos que «apuntarian a 'descronologizar' el 'hilo histórico' y a restituir, aunque no fuera por reminiscencia o nostalgia, un tiempo complejo, peramétrico, no lineal, cuyo espacio profundo recordara el tiempo mítico de las viejas cosmogonías ligado por esencia, también a él a la palabra del poeta o del adivino..." (34).

Además de los citados signos explícitos de enunciación en la narración histórica, y citando de nuevo a Jakobson, Barthes añade que deben observarse los signos referidos a los protagonistas de dicha enunciación: el destinatario y enunciante. En el discurso histórico, los primeros «están generalmente ausentes y sólo se encuentran cuando la historia se presenta como lección» (35), por más que el sujeto de lectura está implicado en todo el discurso, y por supuesto, en el histórico.

"Los signos del enunciante o destinador, dice, son evidentemente, mucho más frecuentes; hay que agrupar allí todos los fragmentos del discurso en que el historiador, sujeto vacío de la enunciación se va llenando de predicados diversos destinados a fundarlo como una persona, provista de plenitud psicológica o más aún de una capacidad» (36); afirmación propia de una lógica estructural no compartida por los planteamientos dialéctos. 
Constata, por otra parte, el predominio de tipos de enunciante característicos en este discurso: el pretendidamente ausente con «carencia sistemática de todo signo que remita al emisor del lenguaje histórico", intentando poner de manifiesto «una historia que se cuenta ella sola» y un discurso histórico llamado «objetivo», donde «el enunciante anula su personalidad pasional pero la sustituye por otra persona, la persona objetiva; el sujeto subsiste plenamente pero como sujeto objetivo» (37).

En segundo lugar, constata «el caso particular en que el enunciante del discurso es al mismo tiempo participante del proceso enunciado; en que el protagonista del enunciado es también el protagonista de la enunciación; en que el historiador, actor en el momento del hecho, se transforma en narradorn (38),

«El enunciado histórico - dice Barthes analizando lo referente al enunciado- debe permitir cortes destinados a determinar unidades de contenido que más tarde podrán ser clasificadas. Esas unidades de contenido representan aquello de que habla la historia; como significados, no son ni el referente puro ni el discurso completo: su conjunto está constituido por el referente segmentado, nombrado, ya inteligible, pero no sometido a una síntaxis» (39).

La constatación y profundación de estas unidades exigen para este autor un trabajo previo encaminado a dilucidar tanto en el enunciado histórico como en el frástico los «exigentes» y los "ocurrentes»: seres, entidades y sus predicados que, en un primer examen «pueden constituir listas relativamente cerradas, es decir, colecciones cuyas unidades terminan por repetirse a través de combinaciones evidentemente variables y pueden permitir ciertas reglas de sustitución y transformación y deben ser posible estructurarlas, tarea más o menos fácil según los historiadores" (40).

Conlleva también, este apartado, el análisis del estatuto especifico del proceso histórico que, a diferencia de otros procesos caracterizables como aseverativos, negativos, interrogativos, etc., "es uniformemente aseverativo, verificativo; el hecho histórico está ligado lingüísticamente a un privilegio de ser: se cuenta lo que ha sido, no lo que no ha sido o lo que ha sido dudoso. En una palabra: el discurso histórico no conoce la negación (o la conoce rara vez y en forma marginal)» (41).

Finalmente, la aproximación al enunciado histórico presupone abordar «las clases de unidades del contenido y su sucesión»: la de los segmentos del discurso que remiten a un significado implícito; la de los fragmentos del discurso de naturaleza razonadora, silogística o, más precisamente, entimé- 
mica, puesto que se trata casi siempre de silogismos imperfectos, aproximativos y la de las unidades que «a partir del Propp se llaman 'funciones del relato', o puntos cardinales desde donde la anécdota puede tomar un curso diferente; esas funciones están agrupadas, sintagmáticamente, en series cerradas, lógicamente saturadas o secuencias» (42).

En resumen, y tras las citadas acotaciones, «puede sugerirse que el discurso histórico oscila entre dos polos según la densidad respectiva de los índices y sus funciones. Cuando en un historiador las unidades indiciales predominan, la historia se ve arrastrada hacia una forma metafórica y se aproxima a lo lírico y lo simbólico... Cuando, en cambio, dominan las unidades funcionales, la historia adopta una forma metonímica, se emparienta con la epopeya» y «existe, en realidad una tercera historia: aquella que por la estructura del discurso intenta producir la estructura de las elecciones vividas por los protagonistas del proceso relatado; en ella dominan los razonamientos; es una historia reflexiva, que se puede llamar también historia estratégica» (43).

Por último, fija su atención en el significado, existente irremisiblemente en el discurso histórico, analizándolo a través de la fragmentación en niveles, al menos dos: el inmanente a la materia enunciada que «retiene los sentidos que el historiador da voluntariamente a los hechos que relata", como pueden ser lecciones morales o políticas obtenidas a partir de ciertos episodios y el que trasciende todo el discurso histórico y se transmite por la temática del historiador. De ahí se deduce que «el discurso histórico de nuestra civilización es esencialmente elaboración ideológica». Con esto se pone en crisis la misma noción de hecho histórico, desde el momento en que interviene el lenguaje y cuando se defiende que el hecho sólo puede ser definido dentro de su existencia lingüística. Esto constituiría un segundo nivel.

Lo anteriormente dicho plantea una última acotación en torno al discurso histórico: ¿qué lugar ocupa lo real en la estructura discursiva? Cuestión despejada en los siguientes términos: «El discurso histórico supone, por así decir, una doble operación harto complicada. En un primer tiempo, el referente está separado del discurso, se vuelve exterior a él, debe fundarlo, regularlo: es el tiempo de la res gestae, y el discurso se presenta simplemente como historia rerum gestarum; pero en un segundo tiempo el significado mismo es desplazado, confundido con el referente; el referente entra en relación directa con el significante, y el discurso, encargado solamente de expresar lo real, considera posible eliminar el significado, término fundamental de las estructuras imaginarias. De esta manera, como todo discurso con pretensión "rea- 
lista", el discurso de la historia cree posible sólo un esquema semántico con dos términos: el referente y el significante; la confusión (ilusoria) del referente y del significado define, como se sabe, los discursos sui-referenciales, tal como el discurso performativo; puede decirse que el discurso histórico es un discurso perfomativo engañoso en el cual el verificativo no es más que el significante del acto del habla como acto de autoridad. En otras palabras, en la historia "objetiva" lo real es siempre sólo un significado no formulado que se refugia tras la apariencia omnipotente del referente. Tal situación define lo que podría llamarse el efecto de realidad" (40).

Resumiendo, pues, el pensamiento del citado autor y completándolo con aportaciones de la ya citada Lingüística Textual, podremos delimitar el texto, discurso histórico, como el complejo significante estructurado según las reglas de competencia textual, semiótica, cuya finalidad es transmitir la visión (historiográfica, ideologizada) que un historiador, a través de un mecanismo lingüístico-retórico, posee de la realidad histórica. Mecanismo de transmisión que implica crear la ficción de la objetividad científica.

Explicitar lo dicho es, simplemente, localizar la historia, el discurso histórico, dentro de la tipología textual, constatando no sólo las implicaciones pragmáticas, sino también los recursos empleados para consolidar la coherencia y cohesión textuales. En resumidas cuentas, estamos diciendo que un texto histórico no puede ser analizado solamente desde la perspectiva de su transmisión de verdad (confrontación referente-texto) que es un semiótica y, podriamos decir, retórica, puesto que como tal texto es básicamente una construcción ideológica de la realidad, hecha a través de mecanismos textuales y determinada, en cualquier caso, por la postura historiográfica del historiador que realiza tal discurso.

Con lo cual estamos exigiendo para el texto histórico una dinámica metodológica, un modelo de análisis similar al del texto narrativo, debiendo aplicar idéntica aproximación textual, literaria (retórica) e histórica, para constatar, en primer lugar, que el discurso histórico desde la Lingüistica Textual ha de ser considerado un tipo de texto, con sus particularidades y concomitancias respecto al resto de texto. Lo que de común tiene con todos los demás se centrará en la constatación de la coherencia-cohesión, pragmática, semántica o morfosintáctica; teniendo en cuenta que dicha coherencia viene determinada por la pragmática, la intencionalidad del emisor empeñado en desarrollar una lógica discursiva histórica y a partir de ahí se elige el aspecto o voz desde donde se presenta a los lectores dicho discurso histórico - crónica, narración, discurso moral, análisis crítico y dialéctico-y, sobre todo, se reali- 
za la elección de la terminología en conexión con el corpus científico, moral, visión del mundo, etc.; la tematización (términos individuales y campos semánticos) y, por supuesto, la propia sintaxis y tono del discurso, en conexión con la entonación y con el modo verbal, ennunciativa, interrogativa, conativa, etc.

El análisis retórico, literario si queremos, es el que hemos realizado siguiendo a Roland Barthes. De sus carencias, más bien respecto a la contextualización y a la determinación social del producto discursivo debidas a la lógica y modelo estructuralista, ha hablado N. Pizarro en estos términos: «Lo esencial es, pues, que la noción de equivalencia gramatical identifica el sentido de la frase con una relación conceptual (una proposición) despreciando asi el efecto significante de la frase como fenómeno del lenguaje ( $y$ no de ideas) que se produce en la realidad práctica. Esta identificación conlleva una concepción racionalista del lenguaje, que va siempre aparejada por una concepción expresiva e instrumental del mismo: el punto de partida del acto de hablar es, en esta concepción, doble. Por una parte, la existencia en la conciencia del sujeto, de una relación conceptual. Por otra, la existencia de una voluntad de significar (un querer decir lo que se piensa). En esto consiste el racionalismo... Deberíamos añadir, una vez más, que el racionalismo y el instrumentalismo lingüístico presuponen un sujeto del habla libre de toda determinación, social o psicológica. El sujeto libre de decir lo que piensa en la forma que elige no existe más que en la ideología. O en los libros de lingüística (iy de ciencias sociales!) (45).

Esto, sin duda, significa una superación del indispensable análisis estructural y semiótico, donde cientificidad se identifica con racionalismo y esto con sistematización (46), abstracción (47) absoluta al margen de las determinaciones sociales: el hecho de hablar, no obstante, ya dijimos, significa más que el significado de los enunciados: significa la relación social reproducida por ellos (48). Es necesario, pues, profundizar para comprender correctamente el discurso histórico en el proceso de historización o culturización que sigue el desarrollo de dicho texto, desde la elección del proyecto hasta la utilización del lenguaje como instrumento de expresión (49).

Para realizar esta operación pueden seguirse modelos diferentes. Nos parece eficaz el que propone $\mathrm{C}$. Segre (50) siguiendo a la semiótica de la cultura soviética, pero, no sería menos eficaz el planteamiento dialéctico que, partiendo de Marx y las explicaciones que en torno a la producción y reproducción ideológica han realizado sus seguidores, expone N. Pizarro aplicándolo a las ciencias sociales y a la propia historia. Brevemente, este autor, tras 
diseñar su tipología discursiva y estudiar las aproximaciones lingüísticas, retóricas, y semióticas al discurso, asi como tratar de profundizar en la propia estructura del discurso literario o sociológico, diseña su paradigma y los supuiestos básicos.

"Los discursos, dice, están modelados a partir de unas prácticas sociales reales» (51), de tal modo que «la ideología es, por lo tanto, en esta perspectiva, la estructura generadora del proceso de producción de los discursos cuyo efecto social específico es la determinación del lugar de los agentes en los procesos sociales y, por lo tanto, en las relaciones sociales de producción» (52). Estos serían los puntos claves en que centra su modelo que resume en un conjunto de propuestas finales donde especifica el largo proceso de creación de discursos desde «los mecanismos, estructuras y procesos que hacen posible que las operaciones efectuadas por el cerebro sobre sus propios estados internos coincidan ampliamente con los procesos sociales objetivos» hasta la elaboración, a través del lenguaje, de los citados discursos, concluyendo del modo siguiente «situados en una larga tradición interpretativa, los intelectuales olvidan con frecuencia que toda producción comprendida como babal, es una relación social. El hecho de hablar significa más que el significado de los enunciados: significa la relación social reproducida por ellos» (53).

\section{POSTMODERNIDAD, HISTORIA, RELATO}

Sentadas las identidades y diferencias entre el texto narrativo y el texto histórico, discursos quizás menos distantes de lo que normalmente se ha pretendido en base a la prejuiciada opinión de acotar el primero como discurso propio de la libérrima voluntad creadora del sujeto, dejando para el segundo la prerrogativa de discurso objetivo que reproduce la realidad o intenta interpretarla, pretendemos al menos sugerir la proximidad existente entre ambos constatando el acercamiento, más que superficial, en la producción actual de historiadores y novelistas por caminos sólo aparentemente paralelos, pero quizás, sería una propuesta de hipótesis, evidentemente cercanos, puesto que, a nuestro parecer, son la reproducción, en línea con la historización de ambos discursos anteriormente delineada, de un paradigma ideológico determinante que, con mayor o menor precisión, llamaremos postmodernidad.

Este paradigma se encuentra a veces desprestigiado por identificársele con unos comportamientos superficiales de carácter eminentemente lúdico. No obstante, y a pesar de no existir - coherente con su lógica de la debilidad (54) - un corpus doctrinal, el paradigma postmoderno posee una historia (55), unos supuestos (56) documentados y divulgados entre otros por el 
filósofo italiano Vattimo, puesto en entredicho por Habermas (57) y, sobre todo, reproducido en discursos específicos: arte, novela, historia, política, etc. (58).

En estos problemas pensaba, sin duda, J. Sádaba, al decir: «No quisiera ser tan ingenuo como para intentar dar una idea completa, una descripción suficiente de la postmodernidad. En primer lugar, porque no suele estar al alcance de uno familiarizarse con la crítica literaria, la socioeconomia, la historia del arte y de la arquitectura, los movimientos vanguardistas, etc. A esta razón subjetiva se añade que es probablemente un pecado de incomprensión intentar definir la postmodernidad. $Y$ es que si alguien está perplejo, si siente que aquello que fue su vida pasada no le sirve, si quiere, en consecuencia, vivir sin prefigurar grandes orientaciones, sería absurdo pedirle una rotunda y delimitada explicación» (59).

Tras estas precauciones, arriesga una somera caracterización:

- Identificación de razón y poder. O, por lo que es lo mismo, en todo lugar se sigue reproduciendo el poder. Al Poder se le opone semejante poder y a la Razón la misma razón aunque poderes y razones actúen «a la contra». Combatir, en fin, el Poder es reproducirlo y en consecuencia, reproducir la Razón misma. Es la llamada paradoja de la revolución.

- El rol grandioso que jugaron la historia o la economía se desplaza, ahora, en favor de categorías supuestamente menos estables y más elementales como es, Vg. la líbido.

- La Historia aparece como un mito más y no como la superación de un estadio mítico. Su logos seria tan mítico como cualquiera de las fábulas que dice suplantar. La Historia, más bien, sería el cuento que nos contamos los hombres blancos para seguir en pie.

- Si la Historia no da más de sí - «el final de la Historia» es una frase con fortuna de la postmodernidad - habría que utilizar otras categorías, otro vocabulario. No es extraño, por tanto, que se hable de esquizofrenia, descodificación, desterritorialización (60).

Características que, explicitadas, significan básicamente que «la Modernidad queda desvalorizada en cuanto que ésta habría sido el gran mito de la razón», es decir, se rechaza el monoteísmo de la razón y se opta por su politeísmo, con lo cual «tendríamos que admitir, en nietzscheanos de nuestro tiempo, que lo único que hay es relato o narración más o menos fabuloso, pero sin fundamentos de origen. Sólo nos cabe describir con la conciencia 
de que de ahí no pasamos; en nada nos sustentamos, no hay Dios pequeño o grande que sea la garantía de nuestro pensamiento y de nuestra acción. Como también diría el Wittgenstein más tardío, el logos, en su voracidad, no ha sido capaz de tomarse por lo que es: uno más en esta historia. Sólo quedaría, por así decirlo, una "lógica de la ocasión", pragmática, sin universalidad que huela a trascendentalismo... Dicho de otra manera: nadariamos en una total fragmentación, en "juegos del lenguaje" o formas de vida con relativa independencia, autojustificadas, sin fundamento ni reposo, dependientes solamente de su propio éxito. No hay, en fin, ni mirada hacia atrás que sustente ni mirada hacia adelante que anime... Efectivamente, el postmodernismo siente lo que Nietzsche pronosticó: el vacío, la soledad de un mundo no sólo sin dioses sino sin hombres fuertes, capaces de hacer de ellos mismos un destino» (61).

Sádaba añade una última acotación de la modernidad al incidir, glosando a Rorty, en su afán de «considerar la esencia del hombre como la de descubridor de esencias en el mundo», para establecer una nueva característica, fundamental, de la postmodernidad, al proponer «una especie de vuelta a la hermenéutica, un arte interpretativo frente a la anquilosada razón. Por hermenéutica no atiende ciertamente un método académico cerrado, una escuela con más o menos adeptos sino el reconocimiento de la diversidad de las razones, de la relatividad de los distintos y encontrados puntos de vista» (62).

Si quisiéramos resumir los planteamientos subrayados deberíamos centrarnos en la consideración del pensamiento débil como supuesto básico de la postmodernidad (63), definido por l. Tono Martínez en estos términos: «Esta metáfora de la debilidad, esta incursión en mi patología particular es interesante porque nos permite alojar el pensamiento postmoderno en su justo lugar: el purgatorio a expensas de lo moderno (el infierno) y lo conservador (el cielo). Parte de las iras que suscita el relato post en ambas instancias de lo divino vienen de esta situación intocable: "está y no está, critica y se evade". Es inaprensible, intocable y su escapismo acentúa su dificultad, su papel mediador y antidefinitorio. Como todo pensamiento reversible es antitotalitario y esto provoca ásperas llagas. En otros países hablan de pensamiento débil y nosotros casi añadiríamos un matiz y hablaríamos de pensamiento enfermo o, a lo sumo, por sus pretensiones, humilde» (64).

En cuanto a nuestra hipótesis de la contigüidad entre el discurso histórico y narrativo, la postmodernidad conlleva, así lo ha estudiado principalmente Lyotard (65), una deslegitimación del discurso «fuerte», dogmático, racio- 
nalista y hasta científico, porque las bases en que se apoyaba han sufrido un profundo descrédito, el metadiscurso del metasujeto, sistematizado y abstracto, ha cedido en favor sin aspiraciones de dogma ni afán de objetividad epistemológica. El relato adquiere sus dimensiones reales y los lectores pueden encontrar los indicios necesarios para no sucumbir al engaño de considerar la ficción como verdad, el discurso como dogma.

Por otra parte, como subraya Jameson, «la desaparición de un sentido de la historia, la forma en que todo nuestro sistema social contemporáneo ha empezado poco a poco a perder su capacidad de retener su propio pasado, ha empezado a vivir en un presente perpetuo y en un perpetuo cambio que arrastra tradiciones de la clase que todas las anteriores formaciones sociales han tenido que preservar de un modo $u$ otro» (66).

Todo lo afirmado desde un punto de vista teórico impone un análisis de algunos ejemplos de la producción histórica y de la narrativa más reciente empleando algunas de las claves citadas a fin de confirmar los supuestos que el paradigma ideológico de la postmodernidad impone en su lectura de la realidad, contemporánea o remota que, desde esta perspectiva, no es tan diferente.

Un supuesto básico de lectura, que ya hemos anotado es la concepción del tiempo, determinante en la elaboración del discurso histórico y narrativo: «Hay dos lecturas, dice J. Ibáñez, del tiempo, Cronos (sólo hay pasado y futuro, el presente es un corte vacío), e lôn (sólo hay presente, que contiene el pasado y el futuro). La postmodernidad va - quizás demasiado- en dirección a lôn: de ahí el énfasis en el "aquí y ahora", de ahí el "carpe diem". Pero tiene en cuenta, por primera vez quizás desde los epicúreos, el presente: el presente que es una intersección no vacía (pues estoy yo con mis recuerdos y mis proyectos) del pasado y el futuro» (67).

Desde ahí, lógicamente, se puede afirmar que la postmodernidad es la época en que empezamos a habitar el mundo real. La sobrevaloración del presente. Esto aparece con bastante claridad en la reciente producción de ciertos historiadores que en sus obras rompen las barreras del tiempo y la ficción del pasado es eliminada: «Iglesia y Estado, Fe y Razón: el juego dialéctico entre estos cuatro elementos - dice Cipolla - se desgrana a lo largo de una historia inmemorial, tanto más enrevesada, por la complejidad de las fuerzas en liza, cuanto que los dos binomios rara vez supieron coincidir. El estado no es necesariamente el adalid de la razón, la Iglesia no es taxativamente sinónimo de Fe y religiosidad no exluye el anticlericalismo" (68). Es decir, el historiador renuncia, en la construcción de su discurso, relato al fin y 
al cabo, a reconstruir o imitar la realidad en su desarrollo cronológico para imponer el presente como tiempo dominante del relato y de la historia, que sucede únicamente en su propio presente, desde el cual estructura la realidad que efectivamente sucedió en el pasado y el lector así lo entiende por los indicios suficientes que el narrador introduce en el texto para que reconozca que se le está contando algo, reivindicación de la historia contada, originaria (69). No existe en este caso el tiempo, sino el narrador que cuenta en su tiempo: el presente.

Si pasamos a la narrativa esto es más evidente y en versiones diversas. Desde los alegatos teóricos que reafirman la tesis de la superación de la categoría tiempo con sus digresiones pasado y futuro como punto clave de la narración novelesca: El Tirano de Taormina («para mí todos los tiempos son el Tiempo... que, como muy bien sabes, en mi cuerpo ha quedado varado») (70), hasta la transgresión radical del mismo, por medio de la ironía donde el pasado se convierte en el pretexto de un juego presente: El rapto del Santo Grial (71); e incluso se llega a prescindir de él, puesto que en la historia, según el narrador, no se trata de contar unos hechos del pasado, sino justificar unos objetivos, la intencionalidad pragmática, del emisor: en las Cruzadas no interesan los sucesos, sino el significado que quiera darles el narrador; el hecho, por lo mismo, pasa por encima de su proceso cronológico a un plano totalmente secundario, reivindicando en cambio su lectura desde la ficción - debilidad - de la vivencia frente a la observación, con lo cual el tiempo del narrador y no de lo narrado es lo que predomina: Mansura («Las libertades que me he tomado con el original eximen de toda responsabilidad a Joinville, pero casi todos los sucesos que aquí se cuentan también los cuenta él.

Resulta muy arriesgado suponer que tal o cual rareza no pudo suceder en el siglo XIII, pero tal otra sí. Quien, llevado por su curiosidad, lea la crónica de Joinville, comprobará cuántas veces lo increíble es más verdadero que lo posible.

Para nosotros, atrofiados por la información, es casi imposible concebir la aventura como algo más que una forma primitiva de expolio, o la sobredosis de disfraz que precisa toda empresa codiciosa. Pero si la aventura sólo fuera negocio y latrocinto, no perviviría. La imaginación es la hermana eterna de la memoria mortal. Es el recuerdo de lo que nunca sucedió, porque nada sucede como es debido. Ojalä este relato renueve la vida de un cruzado que peregrinó a Tierra Santa movido por la codicia, sin duda, pero también por la imaginación») (72).

En algún caso se trasciende el tiempo y lo que fuera pasado se convierte en el punto de partida para una fábula «nacionalista»: Cercamón (73) con in- 
gredientes narrativos de absoluta actualidad. Si nos fijamos en otras novelas podemos observar la manipulación del tiempo histórico, por medio del relato, de tal modo que un fragmento mínimo de la historia adquiere la amplísima dimensión que el narrador le concede: Memorias de Adriano, La muerte de Virgilio (74). Otro problema relacionado con el tiempo, más reciente en este caso, se refiere al tratamiento que Juan Benet en Herrumbrosas Lanzas (75) da a la guerra civil, donde el objeto, el tiempo, quedan de lado, para dar lado a la parodia del absurdo de esa guerra y cualquier otra.

Conectamos, pues, en todos los ejemplos, con el tiempo del narrador sobre el de la historia y del propio relato, el tiempo psicológico por encima del cronológico. Sólo existe el tiempo pensado, el tiempo del autor que se cuenta a sí mismo la historia inventada o recreada y provoca al lector para que realice una operación similar, reduciendo el proceso temporal a su propio tiempo de lectura: «Bueno, mira, la cuestión cronológica no es mi fuerte... Esto le ocurre a todo el mundo, aunque después ponga en marcha la estropeada razón que le ordena los hechos... La realidad es que pensamos y recordamos muy anárquicamente... de repente, un perfume, un murmullo, una palabra, una madalenita, otra palabra, otro murmullo, otro perfume... El orden temporal debe ser cosa vuestra... A mí no me importan las fechas, los antes y después...» (76).

En segundo lugar es imprescindible estudiar, en ambos discursos, las dimensiones del narrador. Discurso histórico y discurso narrativo pretenden radicalmente lo mismo: poner en crisis el modelo racionalista de cualquier texto histórico y cualquier artefacto novelesco, reivindicando frente a la verdad, la verosimilitud; el objeto no existe para el narrador más que como objeto leído: «La actitud postmoderna frente a la historia no renuncia a los métodos analítjcos de las décadas anteriores, pero sí desconfía de las visiones totalizadoras. Cuanto más general, más falso es el discurso y, por lo tanto, más se aleja de esa pretensión de sinceridad que caracteriza a la modernidad. La gran historia se disuelve en muchas historias microscópicas. El objetivo no es ya tanto la verdad como la verosimilitud, la adecuación a las reglas del juego. La historia hoy se afirma como relato y por este camino se acerca al único mundo que no discrimina la ficción frente a la realidad: el arte» (77).

En palabras de otro autor, el papel del narrador es poner en evidencia que lo que hacen la historia y la narración es contar y evidenciar esto es una forma de desmitificar sobre todo el discurso histórico, puesto que lo que se cuenta es un invento del narrador, en ningún caso un producto objetivo; es decir, se deslegitima cualquier discurso, lenguaje al fin y al cabo, como vehículo de verdad que era el afán de la modernidad, tratando de ocultar un discurso manipulado, cuando en realidad «todos los ideales son ilusorios, todos 
los relatos mienten, cada objetivo es un espejismo. Los que corren en post de ideales en vez de pasar al otro lado se estrellan contra el espejo» (78).

La desconfianza, por tanto de la ideología postmoderna frente a toda apariencia de racionalidad y sobre todo de dogma e incluso objetividad lleva a historiadores y novelistas a replantear la configuración del punto de vista o focalización de sus discursos. Se desconfía de las visiones totalizadoras y se minusvalora todo afán de imponer visión alguna del mundo, optando por la propuesta de un discurso débil que permita al lector, reivindicando radicalmente, elaborar su propia lectura.

Esta operación se realiza en ambos discursos de forma similar, si bien en el histórico aún no abunden ejemplos, puesto que tiene demasiado peso el fantasma de la necesaria cientificidad. No obstante, podemos encontrar modelos suficientes y válidos para constatar un camino apenas iniciado. El narrador en tercera persona, pretexto de objetividad, que era el modelo generalizado, es transgredido por algunos autores (79) que intentan prescindir de dicho modelo por una doble vía: la introducción, primero, de acotaciones que patentizan la dimensión subjetiva de su discurso o el cambio de perspectiva historiográfica que implica la introducción de nuevos protagonistas y diversos en el discurso histórico: "Antes era válido acusar a quienes historiaban el pasado, de consignar únicamente las "gestas de los reyes". Hoy día ya no lo es, pues cada vez se investiga más sobre lo que ellos callaron, expurgaron o simplemente ignoraron. ¿Quién construyó Tebas de las siete puertas? pregunta el lector obrero de Brecht. Las fuentes nada nos dicen de aquellos albañiles anónimos, pero la pregunta conserva toda su carga» (80).

En segundo lugar el reconocimiento de voz propia a los diversos protagonistsa de la historia que desean contarnos, no como testimonio de veracidad, sino como plurivocidad discursiva: ¿Quién rompió las rejas de Monte Lupo?, Montaillou, aldea occitana. Por supuesto, este objetivo no siempre se realiza a través del discurso directo, pero, en el estilo indirecto, tal como está configurado, se ve incluida la afirmación anterior.

Un tercer ejemplo indicador de la ruptura con el metanarrador o metasujeto del historiador que aparecía como vehículo de transmisión de la verdad, la realidad, dotado de la omnipresencia y omnipotencia de la selección, de la organización y, por descontado, de la interpretación, podría observarse en la formulación teórica del modelo historiográfico llamado paradigma indiciario y su correlato práctico El queso y los gusanos, donde se concede el protagonismo a la intuición del narrador, detective, frente a la racionalidad o determinación ideológica del historiador científico. 
En cualquier caso, los historiadores contemporáneos pretenden por todos los medios, incluso siguiendo esquemas determinados por la racionalidad historiográfica del modelo que defienden (positivista, Annales, marxista, Nueva Historia), resaltar esta circunstancia, la determinación ideológica de su trabajo, con el fin de alertar al lector respecto de su intencionalidad, lo que constituye, sin duda, una forma de deslegitimación del discurso, al observar con claridad que no presentan la verdad, el referente, sino su visión del mismo.

En la novela esto es más evidente e incluso más acorde con el oficio de narrador en otros tiempos. Básicamente se rompe con el narrador omnisciente que, distanciado del relato, va dirigiendo cada uno de los elementos estructurales del mismo a larga distancia, y se impondrá el narrador en primera persona, aunque se hable de un referente medieval: «Si os ha llegado alguna noticia de los sucesos de estas tierras, me creeréis sin tener que jurároslo, que no me ha faltado ocasión de arrepentirme de haber aceptado llevar a cabo una tarea tan arriesgada. Si el galardón de esta empresa no fuera mi propia libertad y la correspondencia de vida al excelente trato... Debo vencer, pues, la tentación de añadir interpretaciones y comentarios que ahora se me ocurren... Pero, así y todo, temo que los sentimientos que aún permanecen muy vivos en mi corazón enturbien mi razón y nublen mi pecho...» (83).

Este narrador normalmente apoya la credibilidad en su propia experiencia: «He nacido para morir y siendo mi muerte una cosa cierta, tanto que ni Dios puede impedirla sin menoscabo de la justicia, pues si todos los nacidos han de morir, la gracia a uno de ellos concedida sería agravio de todos los restantes, no debo, ni quiero, emplear mis talentos de manera mala. Es por ello que cuanto aquí se diga será verdad y cosa o acontecer que yo mismo he vivido" (84).

Pero la mayor radicalidad del nuevo modelo narrativo proviene de la introducción de la plurivocidad, es decir el enfoque de la realidad tratada desde distintos ángulos de visión, ángulos normalmente simbólicos puesto que un personaje en la novela no es el paradigma de la individualidad, sino el representante del colectivo (85), de tal forma, que no funciona en el relato como vehículo de su propia opinión, sino de la de su grupo o clase.

Insistiendo más en el nuevo narrador como producto de la postmodernidad, defensora del antidogmatismo, reivindicadora de la liberación personal ante el agobio del sistema empeñado en condenar al anonimato a todo personaje, como manifiesto de libertad no sólo de expresión sino también de desinhibición, debemos resaltar el predominio del relato autobiográfico, a veces descarnado, pero siempre ficticio, como modelo narrativos. (86). 
Entremos ahora en el orden del relato o secuenciación y organización de las acciones. Lógicamente este apartado es continuación del anterior y, sin duda, un capítulo básico para dilucidar la hipótesis tanto de que la novela es una forma de discurso histórico como de que el discurso histórico posee una estructura discursiva cercana al relato literario, en cuanto a discurso organizado por el narrador, sustituto del autor-emisor.

Básicamente conviene poner en claro que ambos discursos constituyen la disquisición en torno a la visión de la realidad dependiente de la intencionalidad del autor: en la historia, apoyada por los testimonios elegidos por el propio sujeto emisor; en la novela, basada únicamente en el armazón ficticio o imaginario. Lo que unifica ambos discursos es, sin duda, la determinación pragmática, intencionalidad del proceso de coherencia y de la puesta en evidencia a través de la cohesión del enunciado.

Es necesario, no obstante, recalcar la diferencia, no radical, de ambos discursos en este aspecto: la coherencia, sobre todo semántica, pero también sintáctica, viene definida por el modelo historiográfico, la ideología histórica del emisor narrador en el discurso histórico. La de la narración por los supuestos narratológicos. Esto es, el historiador construirá su discurso apoyándose en la terminología epistemológica propia y elaborará la tematización y los campos semánticos plasmando la visión del mundo que su ideología le impone. La sintaxis, por su parte, responderá a la determinación conceptual: descriptiva, positivista o dialéctica. La estructura discursiva tendrá, en fin, como secuencias básicas, la enunciación de una hipótesis, el desarrollo de la misma y la conclusión pertinente. En consecuencia con sus paradigmas ideológicos se primarán unas situaciones, unos acontecimientos, unos personajes.

El novelista, a su vez, hallará en la visión del mundo, en la ideología, la base de la tematización, tópica por supuesto, de las acciones a resaltar o de los acteantes a responsabilizar, pero el esquema de estructuración aunque básicamente, digamos en la estructura profunda, sea el mismo que el del discurso histórico, dadas las exigencias del modelo de la ficción, la secuenciación habrá de seguir el esquema narratológico: éxito a conseguir, fechoría a cometer, etc., respetando únicamente la verosimilitud.

Quizás, y para finalizar con este análisis, la mayor apariencia de diversidad entre ambos discursos sea el tratamiento del referente, no del referente elegido pues no cabe duda que en esto puede darse una coincidencia, ya que la postmodernidad, la historia social, la Nueva Historia y la narrativa contemporánea están empeñadas en reivindicar el antihéroe, la cotidianeidad, 
la marginación y las situaciones débiles y un tanto insignificantes. Sino que se pretende subrayar aquí cómo la Historia intenta contar, interpretar la realidad $y$, con todos los reparos que podamos poner, busca desvelar los entresijos (modelo causa-efecto) de la realidad.

En cambio, el narrador se siente, por su modelo de ficción imaginario, libre de ese compromiso y el referente, es más bien un pretexto de creación, hasta el punto de que aún siendo reproducida la matriz ideológica en todo momento, siempre se presentará el discurso narrativo como tratamiento del objeto leído, nunca objetivo. No obstante, difícilmente podrán separarse ambos discursos de la operación que se les atribuye desde el paradigma postmoderno, ser traductores de la realidad, aunque en el caso del narrativo sea básicamente irónica.

Resalta, y ya lo recordamos en otra ocasión (87), el afán de reconstruir el medievo. Así lo justifica F. Solano comentando reconstruir la obra de Félix de Azúa, Mansura: «La crónica - la actual, la periodística- es hoy género comodín, aplicable a todo, hasta el punto de contaminar la novela, sin proponérselo, de una verosimilitud que la empobreçe. De ahi, tal vez, la eclosión de crónicas medievales bretonas, islandesas, celtas. Ese interés por la arqueologia literaria contrapesa, al menos, la triste mitología de nuestro tiempo... Azúa se sirve de unos ideales caducos, de una anacrónica moral, de una época fenecida, no para hacer novela histórica. Su intención es didáctica" (88). Del medievo se sirven los autores para ensayar modelos de interpretación (U. Eco), para recrear su ficción (Racionero), para evadirse lúdicamente de la realidad contemporánea (R. Ruiz), para fabular sobre el pasado de un pueblo (M. Onaindía) y hasta para reivindicar problemas actuales ( $P$. Díaz Mas).

Queda, pues, como proyecto de trabajo, como hipótesis a discutir, el que desde la postmodernidad como modelo epistemológico, cualquiera de sus productos, lo postmoderno, están determinados por la debilidad como ingrediente discursivo, debilidad que podría resumirse en la huida de la racionalidad, del dogmatismo o del distanciamiento objetivista para albergarse en la propuesta, a veces provocación de las diversas focalizaciones, puntos de vista, evidenciados en la cohesión de los propios discursos que propalan los supuestos del acercamiento a la realidad, presente o pasada, porque el tiempo es ya una categoría periclitada. La historia, como la novela, serán dos discursos igualmente deslegitimados para las visiones fuertes, válidos en cambio, para la aproximación, en parte diversa en parte similar, al referente, donde la determinación del paradigma ideológico, la intencionalidad del autor y el componente pragmático del relato son datos ineludibles, tal como lo expre- 
san los interlocutores de El Tirano de Taormina: "Todo lo que he dicho corresponde al ámbito mítico-cultural de Creta... y no sé cómo ligarlo con Taormina.

No me vengas con remilgos, Arnaldo. Me ha gustado demasiado tu idea como para que ahora la eches por la borda... No tengas escrúpulos, no los tuvieron ni Homero ni Ovidio, por ejemplo. Las historias más seductoras que jamás haya leído son las Metamorfosis del Nasón: pura y encantadora mentira tras mentira...» (89).

¿Significa acaso todo este planteamiento una transgresión del discurso histórico, entendido como manipulación del objeto histórico por parte del propio historiador, del narrador distanciado de la historia que narra (omnisciente) desvelando ese mecanismo como pseudocientifico o simplemente un idealismo que intenta crear la ficción, postmoderna por supuesto, de la libertad a través de la reivindicación del sujeto narrador en primera persona, o la plurivocidad que implican las prerrogativas de crear un nuevo tiempo, un espacio diferente y unas acciones a su propia medida? Los postmodernos dirán que es la consagración del pensamiento débil frente al absoluto, dogmático y trascendental; nosotros... albergamos nuestras dudas y no descartamos la posibilidad de que constituyan un nuevo artificio de racionalidad, sólo en apariencia carente de sistematicidad. 
(1) BARTHES, R. (1972), «El discurso de la Historia», en VV. AA., Estructuralismo y Literatura, Ed. Sudamericana, Buenos Aires, p. 49.

(2) Será necesario delimitar posteriormente esta arbitrariedad, insistiendo en la determinación sociocultural del proceso de producción del texto narrativo.

(3) BERNARDEZ, E. (1982), Introducción a la lingüística del texto, Ed. Espasa-Calpe, Madrid. PETÜFI, J. S.; GARCÍA BERRIO, A. (1978), Lingüistica del texto y crítica literaria, Ed. Comunicación, Madrid, pp. 19-53.

(4) BERNARDEZ, E. (1982), p. 85.

(5) LOTMAN, Y. M. (1978), Estructura del texto artístico, Ed. Istmo, Madrid.

(6) BERNARDEZ, E. (1982), pp. 90-101. SEGRE, C. (1985), Principios de análisis del texto literario, Ed. Crítica, Barcelona, p. 46 ss. LOZANO, J. et al. (1982), Análisis del discurso, Ed. Cátedra, Madrid, p. 19-33.

(7) AKMAJIAN, A. et al. (1984), Lingüistica: introducción al lenguaje y a la comunicación, Ed. Alianza, Madrid, p. 313-325.

(8) ECO, U. (1981), Lector in fabula, Ed. Lumen, Barcelona.

(9) LOZANO, J. et al. (1982), p. 252.

(10) SEGRE, C. (1985), p. 219.

(11) LOZANO, J. et al. (1982), pp. 22-32.

(12) SEGRE, C. (1985), p. 292.

(13) Cir. nota 12.

(14) PIZARRO, N. (1979), Metodología sociológica y teoría lingüistica, Ed. Comunicación, Madrid, pp. 45-93.

(15) PROPP, V. (1971), Morfología del cuento, Ed. Fundamentos, Madrid. BARTHES, R. (1966), «Introduction à l'analyse structurale des récits", Comunications, 8, pp. 1-27. BREMOND, C. (1976), «El mensaje narrativo» en Comunicaciones, 4, pp. 71-105. GREIMAS, A. J. (1971), Semántica estructural, Ed. Gredos, Madrid.

(16) SEGRE, C. (1985), p. 134-140.

(17) MARCHESE, A.; FORRADELLAS, J. (1986), Diccionario de retórica, crítica y terminologia literaria, Ed. Ariel, Madrid, pp. 199-200.

(18) LOZANO, J. et al. (1982), p. 252.

(19) ROMERA DEL CASTILLO, J. (1980), El comentario semiótico de textos, Ed. S. G. E. L., Madrid.

(20) Cfr. nota 16.

(21) PIZARRO, N. (1979), pp. 131-195.

(22) PIZARRO, N. (1979), p. 237.

(23) SEGRE, C. (1985), p. 142; (1981), Semiótica, historia y cultura, Ed. Ariel, Madrid. 
(24) SEGRE, C. (1985), p. 143.

(25) Cfr, nota 21.

(26) PIZARRO, N. (1979), p. 223.

(27) BARTHES, R. (1972)

(28) BARTHES, R. (1972), p. 48.

(29) BARTHES, R. (1972), p. 37

(30) BARTHES, R. (1972), p. 38

(31) Cfr. nota 30.

(32) BARTHES, R. (1972), p. 39

(33) Cfr. nota 32.

(34) BARTHES, R. (1972), p. 40.

(35) BARTHES, R. (1972), p. 41.

(36) Cfr. nota 35 .

(37) BARTHES, R. (1972), pp. 41-42

(38) BARTHES, R. (1972), p. 42.

(39) BARTHES, R. (1972), p. 43.

(40) Cfr. nota 39.

(41) BARTHES, R. (1972), p. 45.

(42) BARTHES, R. (1972), p. 46.

(43) BARTHES, R. (1972), pp. 46-47.

(44) BARTHES, R. (1972), p. 48-49.

(45) PIZARRO, N. (1979), pp. 139-40.

(46) PIZARRO, N. (1979), p. 68.

(47) PIZARRO, N. (1979), p. 229.

(48) PIZARRO, N. (1979), p. 237

(49) PIZARRO, N. (1979), p. 144.

(50) Cfr. nota 23. LOTMAN, Y. M. (1979), Semiotica de la cultura, Ed. Cátedra, Madrid.

(51) PIZARRO, N. (1979), p. 219

(52) PIZARRO, N. (1979), p. 221.

(53) PIZARRO, N. (1979), pp. 234-237.

(54) VATTIMO, G.; ROVATTI, P. A. (1984), "l pensiero debole, Ed. Feltrinelli, Milán.

(55) TONO MARTINEZ, J. (1986), La polémica de la postmodernidad, Ed. Libertarias, Madrid, FOSTER, $\mathrm{H}$. et al. (1985), La postmodernidad, Ed. Kairos, Barcelona. CARRAVETTA, P.; SPEDICATO, P. (1984), Postmoderno e letteratura, Ed. Bompiani, Milán. VV. AA. (1984), Cuadernos del Norte, 26.

(56) VATTINO, G. (1986), El fin de la modernidad, Ed. Gedisa; Barcelona. (1986 a), Introducción a Heidegger, Ed. Gedisa; (1986 b), Las aventuras de la diferencia, Ed. Península, Barcelona. IBÁÑEZ, J. (1986), «Tiempo de postmodernidad» en TONO MARTÍNEZ, J. pp. 27-67.

(57) HABERNAS, J. (1985, «La modernidad, un proyecto incompleto», en FOSTER, H., pp. 19-37.

(58) Cfr. nota 55.

(59) SADABA, J. (1986), «La postmodernidad existe» en TONO MARTÍNEZ, J., p. 165.

(60) SADABA, J. (1986), p. 167.

(61) SADABA, J. (1986), p. 169.

(62) SADABA, J. (1986), p. 171.

(63) VATTINO, G.; ROVATTI, P. A. (1984), pp. 9-10.

(64) TONO MARTÍNEZ, J. (1986), «Los dos poderes». 43-89

(65) LYOTARD, J. F. (1986), La condición postmoderna, 2. ed., Ed. Cátedra, Madrid, pp. 185.

(66) JAMESON, F. (1985), «Postmodernismo y sociedad de consumo» en FOSTER, H., p.

(67) IBAÑ̃ZZ, J. (1986), p. 59. 
(68) CIPOLLA, C. M. (1984), ¿Quién rompió las rejas de Monte Lupo?, Ed. Muchnik, Barcelona, p. 13.

(69) RUIZ, R. (1980), El tirano de Taormina, Ed. Hiperión, Madrid, p. 20.

(70) RUIZ, R. (1980), p. 17.

(71) DIAZ MAS, P. (1984), El rapto del Santo Grial, Ed. Anagrama, Barcelona.

(72) AZÚA, F. (1984), Mansura, Ed. Anagrama, Madrid.

(73) RACIONERO, LL. (1982), Cercamon, Ed. 62, Barcelona.

(74) YOURCENAR, M. (1983), Memories d'Adrià, Ed. Laia, Barcelona

(75) BENET, J. (1983), Herrumbrosas lanzas, Ed. Alfaguara, Madrid.

(76) RUIZ, R. (1980), p. 27.

(77) RAMIREZ, J. A. (1986), "Catecismo breve de la postmodernidad", en TONO MARTí. NEZ, J., p. 21.

(78) IBÁÑEZ, J. (1986), p. 30.

(79) CIPOLLA, C. M. (1984). GINZBURG, C. (1981), El queso y los gusanos, Ed. Muchnik, Barcelona. Le Roy Ladurie, E. (1981), Montaillou, aldea occitana de 1294 a 1324, Ed. Taurus, Barcelona. SCHMITT, J. Cl. (1984), La herejia del Santo Lebrel, Ed. Muchnik, Barcelona.

(80) GINBURG, C. (1981), p. 13.

(81) Cfr. nota 79.

(82) GINZBURG, C. (1981); (1979), "Spie. Radici di un paradigma indiziario», en GARGA$\mathrm{NI}, \mathrm{A}$. (dir), Crisi della ragione, Ed. Einaudi, Turín.

(83) ONAINDÍA, M. (1985), La tau y el caldero, Ed. Grijalbo, Barcelona, p. 7.

(84) AZÚA, F. (1984), p. 9.

(85) CEBRIÁN, J. L. (1986), La Rusa, Ed. Alfaguara, Madrid. GARClA MORALES, A. (1985), El silencio de las sirenas, Ed. Anagrama, Madrid.

(86) GOYTISOLO, J. (1985), Coto vedado, Ed. Seix Barral, Barcelona; (1986), Los reinos de taifa, Ed. Seix Barral. GOYTISOLO, L. (1985), Investigaciones y conjeturas de Claudio Mendoza, Ed. Anagrama, Barcelona. GUELBENZU, J. M. (1984), El esperado, Ed. Alianza, Madrid.

(87) BERNARDO PANIAGUA, J. M. (1984), «Leyendo el medievo: El nombre de la rosa», Anales de la Universidad de Alicante, 3, pp. 195-236.

(88) SOLANO, F. (1984), "Una crónica medieval» (Recensión de Mansura), Libros, 33-34, pp. $9-10$.

(89) RUIZ, L. (1980), pp. 16-17. 